\title{
Effect of Consumption of Locally Made Micronutrients Rich Laddoos on Nutritional Status of Rural Undernourished Children
}

\author{
(Data from KONKAN region of Indian state of Maharashtra) \\ Suvarna Patil $^{*}$, Charudatta Joglekar ${ }^{2}$, Swati Sonawane $^{2}$, Rupali Chavan ${ }^{2}$, Asawari Modak ${ }^{2}$ \\ ${ }^{1}$ Department of Medicine, BKL Walawalkar Hospital and Rural Medical College, Sawarde, Taluka-Chiplun, \\ District-Ratnagiri, Maharashtra 415606, India \\ ${ }^{2}$ Regional Centre for Adolescent Nutition and Health, BKL Walawalkar Hospital and Rural Medical College, \\ Sawarde, Taluka-Chiplun, District-Ratnagiri, Maharashtra 415606, India
}

*Corresponding Author: Suvarna N Patil, Department of Medicine, BKL Walawalkar Hospital and Rural Medical College, Sawarde, Taluka-Chiplun, District-Ratnagiri, Maharashtra 415606, India. Email:dr.suvarnanpatil@gmail.com

\begin{abstract}
India has witnessed rapid nutrition transition over last 2 decades yet under nutrition is very much prevalent in many parts of the country. Young children in KONKAN region are poorly nourished and according to Developmental Origins of Health and Disease hypothesis, they are at risk of developing non communicable diseases in the adulthood. We investigated nutritional status of 3-6 year old rural children going to day care centres (Anganwadis) and supplemented them with locally designed nutritional supplement (laddoos) for 5 months. We enrolled 1184 children. At baseline the prevalence estimates of stunting, underweight and wasting were $74.4 \%, 91.6 \%$ and $33.3 \%$ respectively. After 5 months of supplementation there was a significant improvement of $8.2 \%$ and $9.6 \%$ in underweight and wasting respectively. $(p<0.001$ for both) but no improvement in stunting. Our results may help public health experts, policy makers in developing the specific strategies to improve nutrition of young children by local means.
\end{abstract}

Keywords: Malnutrition, Laddoos, KONKAN, India, children, anganwadi

\section{INTRODUCTION}

Recent research suggests that factors influencing growth and development in early life (before birth and during childhood) affect long-term health, and the risk of developing adult diabetes and heart disease. The Developmental Origins of Health and Disease (DOHaD) concept suggests that intrauterine as well as extrauterine nutrition affects early growth and development and also influence long-term health [1]. Studies in different populations have shown associations of size at birth and childhood growth with the risk of developing type 2 diabetes and cardiovascular disease [2-5]. It is known that multiple micronutrient deficiencies commonly coexist. In recent years, the major focus of nutrition programs in developing countries including India has been on iron, iodine, vitamin $\mathrm{A}$ and to some extent zinc. Indian government in 1985 as part of the Integrated Child Development Services (ICDS) program to combat child hunger and malnutrition launched the Anganwadi scheme. Anganwadi is a type of rural mother and child care centre in India. Anganwadi means "courtyard shelter" in Indian languages. It also provides basic healthcare in Indian villages. It is a part of public health-care system.

BKL Walawalkar Hospital was established in 1996 in a hilly area at the base of Western Ghats in the village of Dervan of Ratnagiri district in the western state of Maharashtra, India. It falls in the coastal region of KONKAN of western India in a state of Maharashtra. The backbone of the hospital health service is community service. Hospital implements various community programs through well developed network of anganwadis and primary health centres from the district. Hospital runs a Malnutrition program under which children from anganwadis in the district are screened for anthropometry and haemoglobin. Those identified as malnourished 
Effect of Consumption of Locally Made Micronutrients Rich Laddoos on Nutritional Status of Rural Undernourished Children

are supplemented with locally designed oral micronutrient rich supplement also known as laddoos on a regular basis. This manuscripts objective is to evaluate the effect of laddoos supplementation on the nutritional status of malnourished children.

\section{MATERIALS AND MeTHOdS}

Malnourished children were investigated as a part of community program with holistic as well as medical service approach. As a part of holistic service parents are educated about child growth, are provided locally prepared nutritious supplements. Nutritious food preparation demonstrations are held. For the severely undernourished children, nutritious food is supplemented under supervision at hospital for 15 days. In 2018 over the period of 1 year our teams of social workers and medical officers visited 45 anganwadis. Our supplementation study lasted for 6 months. Children with congenital, chronic and acute illness were excluded.

Anthropometry: All the children underwent anthropometry on a monthly basis beginning at baseline before start of supplementation and then on a monthly basis up to 6 months at the completion of the supplementation. Height and weight were recorded by trained nurses of our hospital using portable stadiometer and electronic scale respectively.

Laddoo Preparation: The laddoos were prepared using traditional method under strictly monitored hygienic environment. The ingradients used to make 3 kilogram of flour are listed in table-1. Only locally available ingredients are used in the recipe. About 90-95 laddoos weighing around $30 \mathrm{gm}$ each were made.

Table1. Ingradients used to prepare 3 kilogram of flour for laddoos

\begin{tabular}{|l|c|}
\hline \multicolumn{1}{|c|}{ Cereal grains } & Weight (gm) \\
\hline Wheat & 400 \\
\hline $\begin{array}{l}\text { Finger millet/Eleusine } \\
\text { coracana }\end{array}$ & 200 \\
\hline Amaranth & 150 \\
\hline $\begin{array}{l}\text { Little millet/Panicum } \\
\text { sumatrense }\end{array}$ & 30 \\
\hline Rice flacks & 40 \\
\hline
\end{tabular}

\begin{tabular}{|c|c|}
\hline M+aize & 10 \\
\hline Jowar & 10 \\
\hline \multicolumn{2}{|l|}{ Pulses } \\
\hline Green gram & 30 \\
\hline Soyaben & 20 \\
\hline Gram & 50 \\
\hline Black gram & 100 \\
\hline \multicolumn{2}{|l|}{\begin{tabular}{|l} 
Dry fruits \\
\end{tabular}} \\
\hline Watermellon seeds & 25 \\
\hline Cashewnut oowder & 25 \\
\hline Marking nut kernel & 10 \\
\hline Almond/Prunus dulcis & 50 \\
\hline Pistachio/Pistacia Vera & 10 \\
\hline $\begin{array}{l}\text { Piyal seeds/Buchanania } \\
\text { lanzan }\end{array}$ & 10 \\
\hline $\begin{array}{l}\text { Garden cress seeds/Lepedium } \\
\text { sativum }\end{array}$ & 50 \\
\hline Groundniut powder & 50 \\
\hline Red pumpkin seeds & 10 \\
\hline Dry date powder & 20 \\
\hline Water chest nut & 100 \\
\hline \multicolumn{2}{|l|}{ Condiments } \\
\hline Cardamom & 20 \\
\hline Nutmeg & 10 \\
\hline Saffron & 5 sticks \\
\hline Piper longum & $25 *$ \\
\hline Dry ginger powder & $50^{*}$ \\
\hline $\begin{array}{l}\text { Poppy seeds/Papaver } \\
\text { somniferum }\end{array}$ & $50 *$ \\
\hline \multicolumn{2}{|l|}{\begin{tabular}{|c|} 
Sweets \\
\end{tabular}} \\
\hline Sugar flour & 900 \\
\hline Honey & 20 \\
\hline Jaggery & 50 \\
\hline \multicolumn{2}{|l|}{ Milk products } \\
\hline Ghee & 500 \\
\hline Milk powder & 10 \\
\hline \multicolumn{2}{|l|}{$\begin{array}{r}\text { Ayurvedic } \\
\end{array}$} \\
\hline Withania Somnifera & 5 \\
\hline Tribulus terestris & 5 \\
\hline Glycerrhiza glabra & 5 \\
\hline
\end{tabular}

Nutrient Content of Laddoos: Our laddoo sample was tested for nutrient contents by government accredited National Agriculture and Food Analysis and Research institute located at city of Pune. Copy of the certificate containing nutrient contents is shown in Figure- 1. 
Effect of Consumption of Locally Made Micronutrients Rich Laddoos on Nutritional Status of Rural Undernourished Children

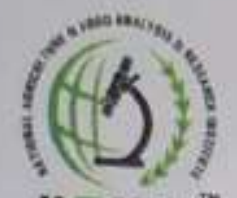

National Agriculture ANd Food Avalysis and ResEarch INSTITUIE

Cosponsored a SUPpoted HAARER OF COMMERCE, INDUSTRES AND AGRICULTURE

Co-spons ored \& Supperted by : MFPI COL SIDBL, NABARD and UNIOO

nctean

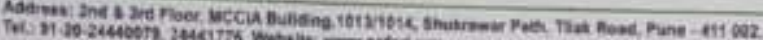

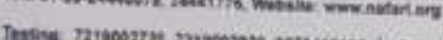

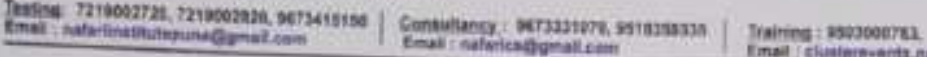

\section{CIN Na. U74220PN2002NPL1017463}

Report No : 17-18/2220

Date of issue : $17101 / 2018$

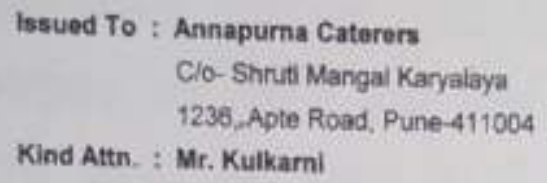

\section{IEST REPORT}

1 Sample Name : Paushtik Laddu (0301182247)

2 Date of Sample Receipt : 03/01/2018

3 Your Ret. No. : Test Request Form

4 Sample Pkg. : Non Commercial Sealed Plastic Box.

5 Sample Collectod By : Client

6 Date(s) of Testing : 05/01/2018 to 12/01/2018

\begin{tabular}{|c|c|c|c|c|}
\hline SR.NO. & PARAMETERS & RESULTS & UNITS & TEST METHODS \\
\hline 1 & Energy Value & 509 & kcalioo o & By Calculation \\
\hline 2 & Protein & 10.05 & $9 / 100 \mathrm{~g}$ & IS: 4079 (Appendix D) \\
\hline 3 & Carbohydrate & 6208 & 97009 & IS: 1656 (Annex C) \\
\hline 4 & Fat & 2452 & $9 / 100 \mathrm{~g}$ & 1S 12220 (Appendix B) \\
\hline $5^{\circ}$ & Iron & 327.83 & $\mathrm{mg} / 100 \mathrm{~g}$ & AOAC $944.02,32.01 .00$ \\
\hline $6^{\circ}$ & Phosphorous & 147,68 & $\mathrm{mg} / 100 \mathrm{~g}$ & IS: 14828 \\
\hline $7 * 3$ & Calcium & 100.27 & $\mathrm{mg} / 10 \mathrm{~g}_{\mathrm{g}}$ & \multirow{3}{*}{$\begin{array}{c}\text { Based on AOAC } 984278 \\
98910,20 \text { th edition }\end{array}$} \\
\hline $8 * 3$ & Magnesium & 105,54 & $\mathrm{mg} / 100 \mathrm{~g}$ & \\
\hline 9.3 & Zine & 13,37 & $\mathrm{mg} / \mathrm{kg}$ & \\
\hline
\end{tabular}

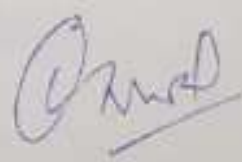

Authorised By - Vinay Oswal

Director

End of Report

Figure1. Nutrient contents and certification 
Distribution of laddoos: Ladoos were distributed at anganwadis where child spends 89 hours since morning. We distributed packet containing 42 laddoos for each child which will last for 14 days as each child was expected to consume 3 laddoos per day (1 in the morning after arrival at anganwadi, 1 at lunch time in noon and 1 before departure to home around 4 pm). Compliance of nutritional supplementAnganwadi midwives recorded the compliance by recording the number of laddoos consumed. A child was considered compliant if the actual consumption of ladoo was at least $75 \%$ of the recommended volume for the entire study period of 5 months.

\section{Statistical Methods}

Data has been presented as mean and standard deviation. Subjects were classified as stunted, underweight or wasted using World Health Organization standards [6]. Those with at least one of these were classified as malnourished. Change in proportions of stunting, underweight and wasting between any two time points was analysed using Mcnemar test.

\section{Ethics}

The study was approved by the Institutional Review Board. Written informed consent was obtained from each child's parents or legal guardian. Our institute ethics committee is registered with the Government of India. Registration code is EC/755/INST/MH/2015/RR18.

\section{RESULTS AND DiSCUSSION}

We studied 1184 children (600 boys and 584 girls) between 3-6 years of age. Laddoos were supplemented to them over a period of 5 months. Thus we have their nutritional status measured using anthropometry at 6 time points (baseline at the $1^{\text {st }}$ month and every month after that up to $6^{\text {th }}$ month). Table 2 shows the age distribution and nutritional status according to age at the baseline when supplementation started. Prevalence of stunting and underweight was very high. There was no gender difference in the nutritional status at the baseline as well as at the end of supplementation. Figure 2 shows nutritional status at every month up to $6^{\text {th }}$ month. There was no change in prevalence of stunting but there was a statistically significant improvement of $8 \%$ and $9.6 \%$ in the prevalence of underweight and wasting respectively $(\mathrm{p}<0.001)$ for both.
Table2. Age distribution and nutritional status of anganwadi children at baseline $(n=1184)$

\begin{tabular}{|c|c|c|c|c|c|}
\hline & & & Age (vears) & & \\
\hline & 3 & 4 & 5 & 6 & Total \\
\hline I & 575 & 336 & 246 & 27 & 1184 \\
\hline Stunting $(n, \%)$ & $419,72.8$ & $247,73,5$ & $192,78,0$ & $23,85.2$ & $881,74,4$ \\
\hline Tnderweight (In, \%) & $491,85.4$ & $326,97.0$ & $240,97.6$ & 27,100 & $1084,91.6$ \\
\hline Wasting $(\mathbb{L}, \%)$ & $179,31,1$ & $120,35.7$ & $85,34,6$ & $10,37.0$ & $394,33,3$ \\
\hline
\end{tabular}
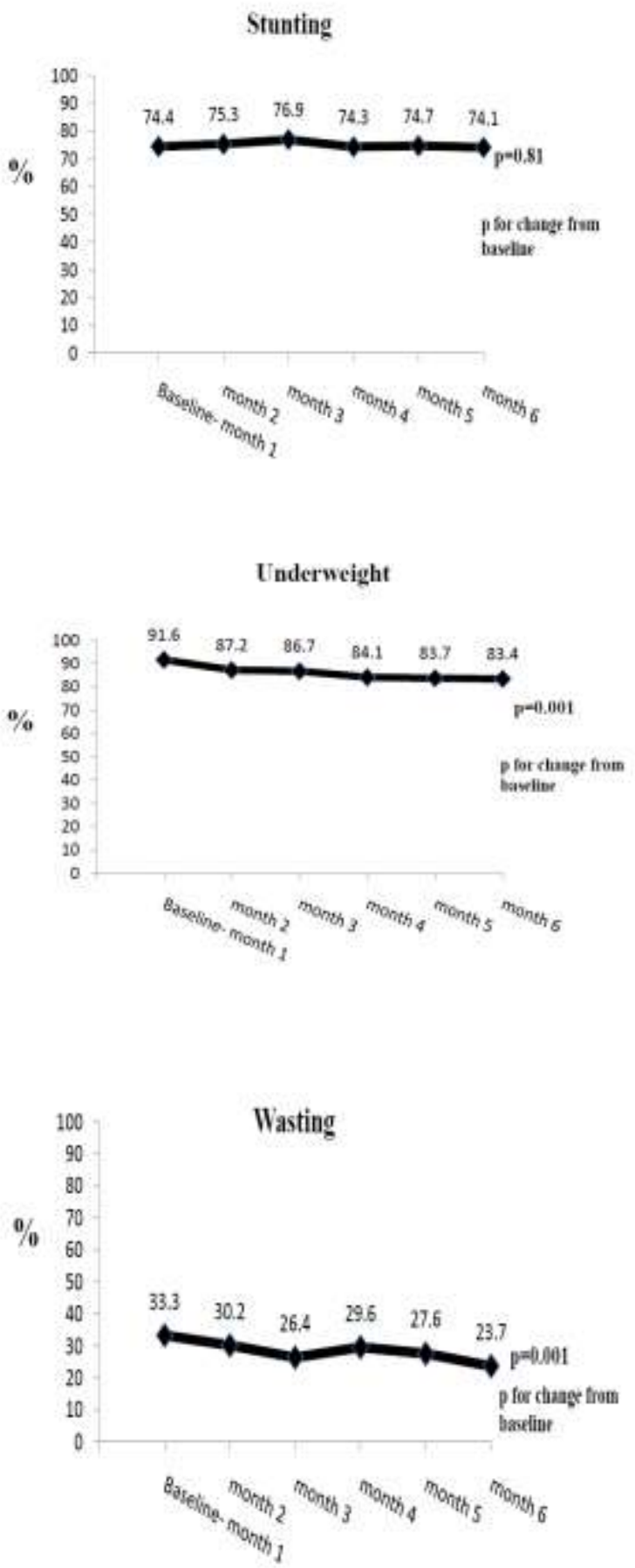

Figure2. Monthly nutritional status during supplementation of laddoos $(n=1184)$ 
This study was our first attempt to show the effect of consumption of locally made micronutrient rich recipe on child growth. All the anganwadis in India are covered under midday meal scheme which is running now for many years but despite this undernourishment is still very high. This is also reflected in the stunting, wasting and underweight incidences in our area among under 5 years of age children [7] and other reports from India.[8-9] Our supplementation was in addition to the mid day meal and it was rich in macronutrients as well as few micronutrients. An adequate and balanced healthy diet during all phases of growth (infancy, childhood, and adolescence) seems obligatory both for adequate growth and development. Increased consumption of caloric, protein, iron, calcium, zinc, and folate during this critical period of rapid growth is desirable. Severe primary or secondary malnutrition can delay the onset and progression of puberty. [10]

In our study, 5 months supplementation using micronutrient rich laddoos showed improvement in nutritional status in terms of underweight and wasting, but stunting status was unchanged. Thus nutritional supplementation was effective for improving weight in nutritionally at-risk, children. Under nutrition has adverse effect on children in terms of physical growth making them prone to childhood diseases as well as puts them at risk for the diseases in the adult hood. It also affects their educational attainment and productivity and ultimately perpetuates poverty [11]. Children throughout the world can reach their growth potential if their caregivers follow recommended health, nutrition and care practices. Stunting indicates a failure to achieve one's genetic potential for height [12]. The main causes of stunting include intrauterine growth retardation, inadequate post natal nutrition and frequent infections during early life [13]. Very short height usually reflects the cumulative effects of poor nutrition across several generations [12]. Under nutrition across various stages of lifecycle has been reported by us in our recent report [14] which shows lack of improvement in stunting in our study. Weightfor-age reflects the effect of the recent as well as long-term nutrition, whereas weight-for-height reflects the recent nutritional experiences. These indices are reasonably sensitive indicators of the immediate and underlying general causes of nutrition [15]. There is an extensive review [16] summarizing the results of administration of micronutrients, singly or in combination to infants, preschool and school children on linear growth. A very small or no benefit was observed for single micronutrient and there was an inconclusive evidence for combination of micronutrients.

There were some limitations in our study. Major limitation was lack of control group which could have enabled us to see the effect of mid-day meals. Anganwadi administrators welcomed our supplementation but there was a resistance from unsupplemnted anganwadis to supply control data. We do not have blood levels of micro nutrients at baseline and after completion of supplementation of laddoos after 5 months. Also we don't have any data on absorption of nutrients in this community.

\section{CONCLUSIONS}

In summary we have shown that supplementation of locally designed laddoos rich in micronutrients improves nutritional status of young children in 5 months. There is tremendous regional diversity of diets in India. Keeping our results in mind, if such supplementation vehicles are used in the various communities across the country taking into account local needs, will impact the nutritional status of young children in positive way.

It is essential for the health workers to be conversant with anthropometric morbidities like under nutrition, wasting and stunting which can adversely affect the growth and development. But this is also a window of opportunity to intervene and correct the condition.

\section{ACKNOWLEDGEMENTS}

The authors would like thank the parents for giving the consent to study their newborn, young children. We would like to extend special thanks to Anganwadi workers who gave us tremendous cooperation to carry out the study.

\section{REFERENCES}

[1] Barker DJP. Fetal origins of coronary heart disease. BMJ 1995;311:171-4.

[2] Barker DJP, Godfrey KM, Gluckman PD, et al. Fetal nutrition and cardiovascular disease in adult life. Lancet 1993;341:938-41.

[3] Warner MJ, Ozanne SE. Mechanisms involved in the developmental programming of adulthood disease. Biochem J 2010;427:33347.

[4] Dabelea D, Pettitt DJ. Intrauterine diabetic environment confers risks for type 2 diabetes mellitus and obesity in the offspring, in 
addition to genetic susceptibility. J Pediatr Endocrinol Metab. 2001;14:1085-91.

[5] Krishnaveni GV, Veena SR, Hill JC, et al. Intrauterine exposure to maternal diabetes is associated with higher adiposity and insulin resistance and clustering of cardiovascular risk markers in Indian children. Diabetes Care 2010;33:402-4.

[6] The WHO Child Growth Standards. http://www.who.int/childgrowth/standards/en/. Accessed February 12, 2020.

[7] http://rchiips.org/nfhs/factsheet_NFHS-4.shtml accessed on February 152020

[8] Krishna A, Mejía-Guevara I, McGovern M, Aguayo VM, Subramanian SV. Trends in inequalities in child stunting in South Asia. Matern Child Nutr. 2018; Suppl 4:e12517.

[9] Kim R, Mejía-Guevara I, Corsi DJ, Aguayo VM, Subramanian SV. Relative importance of 13 correlates of child stunting in South Asia: Insights from nationally representative data from Afghanistan, Bangladesh, India, Nepal, and Pakistan. Soc Sci Med. 2017; 187:144-154.

[10] Kanani S, Consul P. Nutrition health profile and intervention strategies for underprivileged adolescent girls in India: A selected review. Indian J Matern Child Health 1990;1:129-133

[11] Ali SS, Dhaded, Goudar S. The impact of nutrition on child development at 3 years in a rural community of India. Int $\mathrm{J}$ Prev Med. 2014;5(4):494-499.

[12] Dewey KG, Begum K. Long-term consequences of stunting in early life. Matern Child Nutr. 2011;7 Suppl 3(Suppl 3):5-18.

[13] Frongillo EA Jr. Symposium: Causes and Etiology of Stunting. Introduction. $J$ Nutr. 1999;129(2S Suppl):529S-530S.

[14] Patil S, Joglekar C, Chavan R, Sonawane S, Modak A and Pendse A. Trends in Malnutrition Indicators from Birth to Adolescence in Rural KOKAN Region of Western India. Int $\mathbf{J}$ Nutr Sci. 2020; 5(1): 1041.

[15] WHO, Nutrition Landscape Information System (NLIS) Country Profile Indicators: Interpretation Guide, World Health Organization, Geneva, Switzerland, 2010.

[16] Bhandari N, Bahl R, Taneja S. Effect of micronutrient supplementation on linear growth of children. Br J Nutr. 2001;85 Suppl 2:S131S137.

Citation: Suvarna Patil, Charudatta Joglekar, Swati Sonawane, Rupali Chavan, Asawari Modak. Effect of Consumption of Locally Made Micronutrients Rich Laddoos on Nutritional Status of Rural Undernourished Children. ARC Journal of Nutrition and Growth. 2020; 6(2):13-18. DOI: https://doi.org/10.20431/24552550.0602003 .

Copyright: (C) 2020 Authors. This is an open-access article distributed under the terms of the Creative Commons Attribution License, which permits unrestricted use, distribution, and reproduction in any medium, provided the original author and source are credited. 